\title{
EL VOTO VIGILADO. INFLUENCIA Y CONTROL ELECTORAL EN LAS HERMANDADES DE HUELVA DURANTE EL ANTIGUO RÉGIMEN*
}

\author{
POR \\ MANUEl JosÉ de LARA RódENAS ${ }^{1}$ \\ Universidad de Huelva
}

\begin{abstract}
RESUMEN
En la Edad Moderna, incluso en los sistemas políticos absolutistas, hubo numerosas instituciones y corporaciones que adoptaron el voto como un sistema normal de toma de decisiones y de elección de cargos. Entre ellas estuvieron las hermandades religiosas. Sin embargo, a menudo las elecciones no garantizaron la transparencia del procedimiento ni impidieron la monopolización de los cargos. Este artículo estudia los mecanismos de vigilancia y control del voto en las elecciones de las hermandades de Huelva durante el Antiguo Régimen.
\end{abstract}

PALABRAS CLAVE: hermandades; cofradías; elecciones; voto; influencia; control; Huelva; Edad Moderna.

\section{THE GUARDED VOTE. INFLUENCE AND ELECTORAL CONTROL IN THE BROTHERHOODS OF HUELVA DURING THE ANCIEN REGIME}

\begin{abstract}
In the Early Modern Age, even in absolutist political systems, there were numerous institutions and corporations that adopted the vote as a normal system of decision making and election of positions. Among them were the religious brotherhoods. However, elections often did not guarantee the transparency of the procedure nor did they prevent the monopolization of the positions. This article studies the mechanisms of vigilance and control of the vote in the elections of the brotherhoods of Huelva during the Ancien Regime.
\end{abstract}

KEY WORDS: brotherhoods; elections; vote; influence; control; Huelva; Early Modern Age.

Cómo CITAR ESTE ARTículo / CITATION: Lara Ródenas, Manuel José de. 2019. «El voto vigilado. Influencia y control electoral en las hermandades de Huelva durante el Antiguo Régimen». Hispania Sacra LXXI, 144: 521-530. https://doi.org/10.3989/ hs.2019.037

Recibido/Received 01-06-2018

Aceptado/Accepted 16-07-2018

\section{INTRODUCCIÓN}

En las instituciones y corporaciones del Antiguo Régimen, las votaciones ocuparon un papel que no es posible desdeñar y que en nada contradecían el sistema político absolutista en el que normalmente se enmarcaban. Bajo el paraguas del absolutismo, y sin que sirviera de paradoja, muchas reuniones de instituciones se decidieron por

* Investigación enmarcada en el Proyecto I+D de la AEI Historia cultural de la corrupción política en España y América Latina (HAR201564973-P). Ministerio de Ciencia, Innovación y Universidades.

1 lara@uhu.es / ORCID iD: https://orcid.org/0000-0001-7668-0688 mayoría de votos y en numerosos cuerpos el acceso a los cargos y puestos de responsabilidad se determinaban por elecciones. Ello no significa que hubiera en ellas una teoría explícita sobre el ejercicio de la representatividad, pero sí que en todas esas corporaciones se votaba y elegía con naturalidad, sin necesidad de trasponer dicha práctica al sistema político general.

Por eso, cuando el onubense José Isidoro Morales, uno de los matemáticos que reflexionó a fines del siglo XVIII sobre los métodos electorales, publicó su Memoria matemática sobre el cálculo de la opinión en las elecciones, advirtió en su prólogo que "se dexa entender que el obgeto de esta Memoria interesa generalmente, pero muy en 
particular a los Tribunales, Cabildos, Universidades, y demás Comunidades y Cuerpos, así seculares como eclesiásticos y literarios, donde las elecciones se hacen por votos" (Morales 1797: s/p). El libro iba dedicado a Manuel Godoy y fue recibido aparentemente sin recelo alguno, a pesar de que en esas fechas el voto político en la Francia revolucionaria ya estaba establecido. Aunque la frase de Morales iba lógicamente cargada de prudencia en tiempos complejos, era verdad que en muchas corporaciones el voto estaba regulado desde antiguo como forma de acceder a un cargo o adoptar una decisión y que se ejercía en todos los casos con el beneplácito de la tradición.

Eso ocurría en las hermandades religiosas, en cuya mayor parte, en principio, era el cabildo general o reunión de todos los hermanos el encargado de elegir a sus oficiales cada cierto plazo de tiempo, que normalmente estaba estipulado en un año. En eso seguían el mismo esquema que habían establecido ya los gremios, como recoge Rumeu de Armas (1981: 189). Naturalmente, esta elección debía garantizar en teoría la rotación de los hermanos al frente de las estructuras de gobierno comunitario, evitando así la monopolización, fosilización o ejercicio incontrolado de los cargos, pero la realidad es que no lo garantizaba. A veces el propio sistema resultaba ser muy cauto ante la posibilidad de que cualquier hermano accediera a los puestos de responsabilidad, multiplicando los controles y vigilancias. Otras veces era la práctica cotidiana la que alteraba y restringía las disposiciones formales de los estatutos. Al final, como resultado, solo tenía capacidad de desempeñar los cargos un pequeño sector de la hermandad, haciendo que la representatividad de los puestos electos fuera bastante más escasa de lo que aparentaba.

Vamos a examinar tales disposiciones y prácticas en el conjunto de hermandades de las que podemos encontrar datos en la Huelva del Antiguo Régimen, si bien en su mayoría son de procedencia indirecta, dado que escasean las cofradías que han conservado parte de su patrimonio documental. Así, excepción hecha de las relativas a la hermandad del Santo Entierro, de la que ha quedado un libro de acuerdos que hoy guarda el Fondo Diego Díaz Hierro del Archivo Municipal de Huelva, las informaciones de las demás hermandades que aquí analizamos provienen de sus reglas, impresas o manuscritas, o de referencias dispersas: algunas proceden de los pleitos pertenecientes a la sección de Justicia del Archivo Diocesano de Huelva y otras de los libros de visita que custodia el Archivo Arzobispal de Sevilla. A manera de mosaico, incompleto por lo demás, hemos manejado datos de las hermandades de San Blas, Santo Tomás Apóstol, Santa Ana, Ánimas del Purgatorio, Santo Entierro, Nuestra Señora de la Cinta, Nuestra Señora del Rosario, Santísimo Sacramento de San Pedro, Santísimo Sacramento de La Concepción, Jesús Nazareno, San Antonio de Padua, Nuestra Señora de los Reyes, Santísimo Rosario, Nuestra Señora de la Caridad y Dulce Nombre de Jesús, además de la hermandad tercera de San Francisco de Asís y de las esclavitudes de la Merced y los Dolores, esta última también llamada de los Servitas. No son, por supuesto, todas las que hubo en Huelva en los siglos $\mathrm{XVI}, \mathrm{XVII}$ y XVIII, pero son las que han dejado mayores testimonios, pues otras tuvieron una vida lánguida o efímera y se fundaron y desaparecieron, al margen de toda oficialidad, sin dejar más rastro que el de su propia existencia.

\section{LAS ELECCIONES COMO INSTRUMENTO DE INFLUENCIA Y CONTROL}

La primera evidencia de la falta de garantías del sistema de elecciones en las hermandades es precisamente esta: la ausencia de vida oficial de un buen número de ellas. Numerosas hermandades del Antiguo Régimen funcionaron, en efecto, al margen de cualquier tipo de estatutos o reglas, con lo que carecieron de un marco normativo estable. Aunque las constituciones sinodales del arzobispado de Sevilla estipulaban en 1604 que los visitadores «miren las reglas, i ordenanças que tienen; si son justas, i pías, i conforme a derecho, y a nuestras constituciones; i quiten las que no se hallaren aprovadas por nos o por nuestro Provisor, procediendo con censuras contra rebeldes, i dando aviso de los tales, si fuere menester» (Constituciones 1609: 142 r.), lo cierto es que muchas hermandades se mantenían sin reglas o no las remitían al arzobispado para su aprobación, como medio de obstaculizar o retardar una supervisión eclesiástica nunca bien recibida.

En la Huelva de 1652, por ejemplo, la hermandad de San Blas reconocía que su asociación «no es cofradía ni tiene regla ni obligación alguna, más que tan solamente una deboçión de vezinos de esta dicha villa», ${ }^{2}$ y, tres años más tarde, los beneficiados onubenses declararían que los cofrades de Santo Tomás Apóstol, del oficio de leñadores, están unidos «por devosión, sin obligación de hermandad ni cofradía». ${ }^{3}$ No obstante, ni a la hermandad de San Blas ni a la de Santo Tomás Apóstol les impedía ello denominarse a sí mismas hermandades o cofradías, hacer fiestas votivas, salir en procesión o tener con regularidad hermanos mayores o mayordomos. En cambio, se hallaban fuera de la vigilancia del visitador arzobispal y, sobre todo, no estaban obligadas a rendir sus cuentas ni a dar explicaciones de lo que decidían. Eso sí, lo que los hermanos de estas asociaciones ganaban en independencia respecto a injerencias externas lo perdían en cuanto a posibilidad de exigir pulcritud en los métodos por los que se elegían internamente a sus oficiales, dado que no había más regulación que la que tenían de uso y costumbre, por lo que era difícil reprimir abusos y presiones en el nombramiento de los cargos o corruptelas en el manejo de sus caudales, estando indefensos ante ellos. Tan a menudo se dio el caso de hermandades funcionando sin control eclesiástico ni estatutos aprobados, que en la visita pastoral de 1623 solo se contaron oficialmente 12 cofradías en la villa de Huelva, ${ }^{4}$ cuando consta que existían al menos 23, además de tres hermandades terceras (Lara 1989: 22-23).

La existencia de unos estatutos era, inicialmente, un aval de transparencia en los procedimientos electorales, pues el sistema de las votaciones solía estar explicitado en ellos, frente a la tentación arbitraria. Sin embargo, es evidente que, a menudo, las regulaciones constituían también un instrumento eficaz para introducir mecanismos de supervisión

2 Archivo Diocesano de Huelva (ADH), Justicia, Huelva, leg. 29, exp. 4, Solicitud de la hermandad de San Blas al arzobispado de Sevilla para la reparación de su ermita, 1652, fol. 3 r.

3 ADH, Justicia, Huelva, leg. 29, exp. 5, Pleito de «la cofradía de Santo Thomás de la villa de Huelba con la cofradía de San Antonio de Padua, hermandad de San Christóbal, San Blas y San Juan Baptista sobre preçedençia», 1655, fols. 3 v. y s.

4 Archivo Arzobispal de Sevilla (AAS), Visitas pastorales, leg. 1.332, Visita pastoral de Francisco de Vallejo Solís, 1623, s/fol. 
y restricciones a la hora de elegir y ser elegido cargo de la hermandad o, al menos, mostraban un fuerte deseo de control a fin de evitar situaciones no deseadas por la autoridad eclesiástica o por los hermanos más poderosos. En manos del arzobispado ( $y$, desde 1768, del Consejo de Castilla), la potestad de aprobar, corregir o interpretar los textos de los estatutos constituía un poderoso vehículo de intervención en el funcionamiento de las hermandades, sus cuentas económicas y los modos de acceder a su gobierno, que procuraba que las asociaciones religiosas dispusieran de estabilidad institucional y mostraran respeto a la jerarquía.

No siempre el voto, desde luego, fue la fórmula elegida para garantizar la representatividad de los cargos respecto al cabildo de hermanos. De hecho, ni siquiera todos los teóricos del pensamiento político estaban entonces ni están hoy de acuerdo en que un gobierno representativo sea necesariamente el resultado de un sistema de votaciones (Syntomer 2012). Hay quienes defienden el turno o la insaculación como métodos más transparentes de acceso a los cargos, pues la rotación o el azar podrían estar en mejores condiciones que la votación para sortear determinados obstáculos a la hora de elegir con libertad, como la coacción, la influencia social y económica y la mayor o menor capacidad del elector. En la propia Huelva, ya el Cabildo municipal había tenido que utilizar el turno y el sorteo para la elección de los cargos, según habían establecido las ordenanzas del duque de Medina Sidonia para el gobierno de sus estados, dadas en 1504. Así debían elegirse los dos alcaldes onubenses de acuerdo con tales ordenanzas:

Escriban los nombres de los rexidores en papeles iguales e doblados igualmente, y aquellos echen un bonete, y el primero niño que pasare por la calle de doce años abajo saque uno de los dichos papeles para alcalde, e aquel lo sea aquel año, desde el dicho primero de henero. Y el que así fuere alcalde no se heche en suerte, salvo los otros. E así se haga por la misma forma, por manera que todos trece han de ser alcalde el año que les cupiere. E porque el otro alcalde ha de ser de los contiosos, mando que se escriban así mismo todos los vecinos de la mayor contía y se pongan sus nombres de la manera susodicha, e saque el niño el papel, e aquel que cupiere sea alcalde de aquel año, e no entre en suerte fasta que ande por rueda de todos (Galán 2004: 99).

Como se ve, era un sistema combinado de insaculación y turno, en el que el sorteo servía solo para establecer el orden del acceso a los cargos, dado que el conjunto de los elegibles estaba cerrado y todos habían de pasar por dicha responsabilidad antes de que cualquiera de ellos repitiese. Obviamente, la transparencia del sorteo era absoluta, pero solo se admitía en casos de turno cerrado. A los vecinos que no perteneciesen al selecto grupo de los regidores o de los "contiosos» no se les permitía acceder a las alcaldías y, ya que ese hecho estaba asegurado, la insaculación se convertía en una práctica totalmente inocua a los ojos del duque.

Eso ocurría también en algunas hermandades de Huelva en las que la extracción social de sus miembros era homogénea, caso de la hermandad de clérigos de Santa Ana, para la que está acreditada la existencia de un turno. Lo refería en su testamento de 1775 el presbítero y notario apostólico Francisco de Torres y Esquivel, al aludir a que era «hermano de la venerable hermandad de señores sazerdotes clérigos de mi Señora Santa Ana de esta villa, sita en dicha iglesia, y por turno de tal hermano fui mayordomo» (González 1995: 204). En estas hermandades de clérigos, en las que no existía especial preocupación por la calidad de los hermanos que accediesen a los cargos, se podían incluso dar sistemas de elección tan poco controlables como el que atestigua, por ejemplo, López Vacas (2014) para Fuente de Cantos: en la cofradía clerical de San Pedro, para elegir a sus oficiales, se introducían en un sombrero cédulas escritas con el nombre de cada hermano; el que resultaba elegido por sorteo nombraba a otro oficial y así unos nombraban a otros, sucesivamente, hasta que se ocupasen todos los puestos. Si los hermanos, en cambio, eran socialmente desiguales, lo habitual entonces era que, huyendo del azar o del turno, la elección de los cargos se realizase mediante un sistema de votaciones.

Podría pensarse que, en abstracto, unas elecciones en una hermandad conformaban un sistema difícil de controlar por parte de la autoridad eclesiástica o de los hermanos de más alto nivel social, pero es evidente que existieron múltiples mecanismos para condicionar los resultados y que en no pocas ocasiones la aparente pureza de las elecciones escondió negociaciones o determinaciones previas a las votaciones, ya fuera apoyándose en unos estatutos especialmente preparados para limitar la voluntad del electorado, ya fuera vaciándolos de contenido. Por lo que sabemos por Mira Caballos y De la Villa Nogales, hubo hermandades en Carmona en las que el sistema de elecciones no se asentaba sobre el principio de "un hermano, un voto", sino que los cargos salientes tenían la posibilidad de tener dos, tres, cuatro o más votos. Eso sucedía en la de Jesús Nazareno, cuyas reglas de 1597 establecían el siguiente reparto: «los hermanos tenían un voto, los oficiales y diputados dos, los alcaldes tres, $y$, finalmente, el hermano mayor cuatro, previéndose además un voto más para este último por cada 25 que hubiese» (Mira y Villa 1999: 48). Esa disimilitud en el número de votos disponibles hacía que, cuando el cabildo de hermanos no acudía en número suficiente a votar, el gobierno de la hermandad podía predeterminar el resultado de las elecciones con bastante facilidad.

No hemos visto en Huelva un caso tan flagrante, pero sí la existencia de instrumentos más sutiles de vigilancia y control de las votaciones. De entrada, cuando las hermandades elegían sus cargos por mayoría de votos, eran el vicario y su notario apostólico quienes presidían los cabildos electorales y las tomas de cuentas a los mayordomos salientes, siendo sustituidos, en ausencias y enfermedades, por el cura más antiguo de la villa y cualquier otro notario apostólico de ella. Como se ha comprobado en el caso de Granada, los conflictos más enconados entre las hermandades y la clerecía procedían precisamente de la exclusión que en ocasiones se hacía de los eclesiásticos en los cabildos de hermanos y en las sesiones electorales (López 1992: 65). En términos generales, sin embargo, el vicario solemnizaba con su asistencia la presencia de la autoridad arzobispal y servía de árbitro ante posibles diferencias, a la vez que debía aprobar los resultados tanto de las elecciones de cargos como de las cuentas tomadas. En los libros de la cofradía de Nuestra Señora de la Caridad se incluyó, a este respecto, «un auto que pareze firmado del licenziado Gaspar Ramírez de Paredes, comisario 
del Santo Oficio y vicario que era desta villa, aprovando el nombramiento de mayordomo, acompañado y escrivano». ${ }^{5}$

Las elecciones, por tanto, estaban sujetas a la autoridad del vicario, quien imponía con su presencia el sentido jerárquico de lo que se estaba haciendo y vigilaba para que el orden no se pervirtiera ni las votaciones dieran lugar a conflictos ni a resultados extraños. Es más, había reglas que introducían al vicario en una posición más activa, reconociéndole incluso un derecho a intervenir en asuntos definitorios de la hermandad. El capítulo primero de los estatutos de la cofradía de Nuestra Señora de los Reyes era bien explícito cuando señalaba la necesidad de que presidiera los cabildos de elecciones «el vicario que es o fuere desta villa, y en su falta el cura más antiguo, y, estando discordes los hermanos en los votos para la dicha elección de mayordomo, lo pueda nombrar el vicario o cura más antiguo que presidiere $» .{ }^{6}$ Cuando se trataba de hermandades que, como las terceras y las esclavitudes, no estaban sujetas a la jurisdicción ordinaria del arzobispado sino que dependían de una orden religiosa, la figura del vicario era sustituida por la de un padre comisario. Haciendo las veces de capellán, era más que un capellán. Fraile del convento donde residía la hermandad, estaba nombrado directamente por el prior conventual y presidía las elecciones anuales de cargos (que él mismo convocaba), interviniendo incluso en la designación de los candidatos que eran sometidos a elección. En general, esta presencia del clero presidiendo las elecciones funcionaba como un recordatorio permanente de que los resultados habían de satisfacer ciertas exigencias religiosas y sociales.

Es verdad que la mayoría de los sistemas electorales de las hermandades reconocían un voto a cada hermano, en principio parece que reservado solo a los hombres. Salvo en el caso de algunas hermandades vinculadas a la clerecía o a hombres de especial distinción y posición social (caso de la del Santo Entierro, especialmente tras su reforma de 1766), las mujeres fueron miembros de las cofradías con completa normalidad, pese a lo cual, en la Huelva del Antiguo Régimen, no consta que hubieran accedido nunca a sus cargos ni que hubieran votado. Cierto que en las reglas y cláusulas fragmentarias de estatutos que han pervivido hasta nuestros días no existen limitaciones a las mujeres respecto a la posibilidad de elegir y ser elegidas, pero ese hecho carece de auténtica significación, porque lo cierto es que siquiera se les nombra. Es obvio que las reglas no las mencionan ni limitan sus derechos porque se da por asumido - sin necesidad de ponerlo por escrito- que las mujeres no participan de ninguna manera en estos mecanismos electorales y no se les da capacidad alguna de representación ni de decisión. En general, es lo que ocurre en otros lugares, salvo en aquellas escasas hermandades exclusivamente formadas por mujeres, en las que estas eran electoras y elegibles, excepto para el cargo de secretario, que recaía normalmente en un varón (Franco 1995: 187-188). Silvia María Pérez González ha hallado a una mujer ocupando en 1471 la priostía de la cofradía de Santa María de Jerez de la Frontera (Pérez 2016: 509) y David Carbajal López también

5 ADH, Justicia, Huelva, leg. 304 (ant.), Pleito de «la hermandad de Nuestra Señora del Rosario de la villa de Huelva con el vicario de dicha villa sobre asistencia a los cavildos», 1727, fol. 109 r.

6 Ibídem, fol. $78 \mathrm{v}$. ha encontrado a algunas mujeres desempeñando cargos menores en las hermandades de Sevilla de fines del Antiguo Régimen (normalmente camareras, enfermeras o mayordomas de insignias). Solo en la hermandad de Ánimas de Villamartín se daba la posibilidad a las mujeres de acceder a la secretaría (Carbajal 2016: 70).

Ese voto que, en condiciones normales, tenía cada hermano varón debía, en principio, ser secreto. Así lo establecían la hermandad de Nuestra Señora de los Reyes y la del Santo Entierro, que en sus actas solía referir que, "haviéndose votado en secreto los demás concurrentes», habían salido elegidos sus directivos «por mayor número de votos». ${ }^{7}$ De todas formas, cuando en las elecciones participaba un número reducido de hermanos (y era lo habitual), el secreto del voto no era algo que pudiera mantenerse con facilidad, lo que posibilitaba la existencia de presiones y coacciones de distinto tipo. Eso ocurría, por poner el caso, en el propio Santo Entierro, pues, después de la reforma que sufrió en 1766, su número de hermanos estuvo limitado a un máximo de 50 seglares y 33 eclesiásticos (Díaz 1972: 94). En esas condiciones, y dado que la mayor parte no solía acudir los cabildos de elecciones, el secreto del voto era a veces pura ficción.

Lo era, en especial, en hermandades en las que la extracción social de sus miembros era mayoritariamente baja, pues los altos índices de analfabetismo hacían imposible la existencia de un voto secreto mediante la escritura o la lectura de un nombre en una papeleta o cédula. Cualquier alternativa a esta modalidad de voto iba en detrimento, por supuesto, de su ejercicio en secreto. Con todo, las reglas solieron prescribir el voto por escrito para las elecciones de cargos y encargaron a los secretarios o sacristanes el repartir y recoger las papeletas. Tal como estipulaban las reglas de los Servitas,

el Secretario cuidará de hacer las cédulas con los nombres de los propuestos, y cortarlas hasta las puntas, para que el hermano pueda tomar el nombre del que juzgare más a propósito. [...] los Sacristanes repartirán las cédulas, y acabadas de repartir, dirá el Padre Comisario: Ahora se hace Elección de Prior, se saldrán los propuestos de la sala, si allí estubieren, y los Sacristanes con unas caxillas recogerán los votos, o cédulas; las quales llevarán a la Mesa del Padre Comisario, y Prior, y averiguando quién tiene más votos, le publicarán por Prior, diciendo: El Hermano N. ha tenido más votos, y así queda electo Prior. Del mismo modo se elegirán los demás oficiales mayores (Reglas 1774: 17).

Cabe preguntarse qué se hacía en los frecuentes casos en que el hermano era analfabeto y no podía leer el nombre que constaba en la cédula, pues nada recogían los estatutos. Conocemos otros casos en que sí había prevista una segunda opción para sortear el problema: los estatutos, por ejemplo, de la hermandad de Santa Ana de Panamá, estudiados por Carmen Mena, introducían la advertencia de que, «mediante que la mayor parte de los cofrades no saben leer ni escribir por lo cual no se pueden hacer las elecciones por cédulas», podían los hermanos emitir su voto pronunciando de viva voz el nombre del candidato. Sin la posibilidad de

7 Archivo Municipal de Huelva (AMH), Fondo Diego Díaz Hierro, Libro de acuerdos de la hermandad del Santo Entierro y Nuestra Señora de la Soledad, fol. 34 r. 
que fuera secreto, la libertad del voto así emitido quedaba totalmente a expensas de las coerciones existentes (Mena 2000: 137).

Todo eso está en la base de la facilidad con la que una elección donde cada hermano disponía de un voto se convertía en la sanción de un resultado ya preparado, fruto de un acuerdo logrado mediante el consenso o la presión. Isidoro Moreno ha comprobado lo mismo en su estudio sobre la hermandad de los Negritos de Sevilla y recuerda que,

aunque la Regla establece un sistema de elecciones plenamente democrático, que contrastaba con la estructura fuertemente jerárquica y con muy poca movilidad social de la época, el cabildo anual de elecciones tenía, de hecho, la función de dar un espaldarazo ritual al acuerdo previamente consensuado entre quienes tenían interés y posibilidades de acceder a los cargos (Moreno 1997: 127).

En la hermandad del Santo Entierro, ya hemos dicho que los cargos eran elegidos por mayor número de votos. Sin embargo, examinando en un plazo medio el resultado de los comicios, la existencia de un turno implícito entre los cargos electos no admite duda: la rotación de clérigos y seglares al frente de los oficios de mayordomo y de acompañado (su sustituto y representante en ausencias) y la regularidad con la que el mayordomo entrante coincidía con el acompañado saliente eran la evidente consecuencia de un turno tácito que las elecciones tenían la misión de oficializar. De lo que se trataba, en suma, era de un sistema electoral consensuado, en el que las candidaturas propuestas eran aceptadas o negociadas con anterioridad al hecho mismo de la votación y donde existía un orden que el cuerpo electoral asumía y ratificaba regularmente: elección en la forma, turno en el fondo.

Al final, la propia cofradía del Santo Entierro acabó reconociendo en acta la existencia del turno. Sin abandonar formalmente el sistema de elecciones vigente, en el cabildo general de 1817 se declaró que los hermanos, «juntos como lo an de uso y costumbre en su ermita a efecto de nombrar acompañado para el año próximo benidero, dijeron que correspondía por su turno a don Francisco Ramos Moreno». Más explícita aún de la coexistencia del turno y la elección resulta el acta de 1830: «Se acordó que, según el orden de entrada, pertenece a don José García ser mayordomo en el presente año, el qual quedó electo, y por el mismo orden de antigüedad quedó electo para su acompañado don Juan Fernández». 8

Claro que un estricto orden de antigüedad en la hermandad (en este caso en dos cuerpos separados que van alternando, el de los eclesiásticos y el de los seglares) para el acceso a los cargos de responsabilidad podía valer para una cofradía, como la del Santo Entierro, cuyos componentes procedían todos de la misma capa social: no en vano, el vicario de Huelva afirmaba en 1786 que sus hermanos «son las personas más condecoradas deste pueblo» (Lara 1998: 85). Sin embargo, ese turno, por vincular a todos, parecía entonces impensable para cualquier otra cofradía de extracción social vertical. Asumido el hecho de que los cargos de una hermandad pertenecían a sus sectores cultural,

\footnotetext{
8 Ibídem, fols. 60 r. y 77 v.
}

económica o socialmente más influyentes, el turno o circulación de los mismos siguió por lo general una línea mucho más restrictiva.

Pero había otros mecanismos que encorsetaban las votaciones. En primer lugar, un cuerpo electoral carente de censo y normalmente poco participativo. Hay que reconocer que, a pesar de la teórica cumplimentación de los libros de hermanos, las cofradías no controlaban realmente cuántos ni quiénes eran sus miembros. Es decir, no se conocía el censo de votantes. "Que para saber los hermanos que somos se forme lista por el secretario (...) y se conozcan lo son legítimamente», estableció en 1808 la hermandad del Santo Entierro. ${ }^{9}$ Sobre esta base, la incomparecencia de los hermanos a los cabildos era algo casi inevitable. Cierto es que, en alguna ocasión, como en 1585 en las elecciones de la hermandad del Dulce Nombre, se reunieron a votar o presenciar las tomas de cuentas «la mayor parte de los hermanos", ${ }^{10}$ pero eso no era lo normal. Tan inquietantes llegaban a ser las ausencias en la cofradía de negros de Nuestra Señora del Rosario, que se tuvo que incluir en los estatutos la siguiente advertencia: que «el cofrade que no viniese a este cavildo de elección de ofiçiales pague de pena una libra de zera». ${ }^{11}$

Cuestión inútil. La propia hermandad del Santo Entierro y Nuestra Señora de la Soledad asistió a la caída irremisible de sus niveles de participación electoral y su cabildo de 22 de abril de 1808 (en el que, además de elegirse los cargos, se realizaron ciertas reformas) solo llegó a registrar la presencia de cinco hermanos, "no haviendo concurrido los demás cofrades aunque para ello se les ha citado». El que tuviera efecto el cabildo, se eligieran los cargos y se llevaran adelante las reformas demuestra la naturalidad con la que se admitió la situación y, aunque esta vez se tuvo el escrúpulo de establecer en acta «que el mismo secretario forme apunte para los hermanos que no han concurrido a este acuerdo, con inserción destos capítulos, para que a su continuación expongan y firmen si están conformes a continuar en la hermandad baxo lo que ellos contienen o se separan de ella, para en su vista determinar», solo se añadieron con posterioridad tres firmas más. ${ }^{12}$ Debe tenerse en cuenta que, en ocasiones, el número de hermanos de una cofradía llegaba a ser exiguo y que no era raro que no fuera posible más reparto de cargos que el que tenía efecto. La caricatura más extrema de esto es la que reconocía en 1776 «don José Garzón, de esta vecindad, mayordomo actual de la cofradía del Santíssimo Sacramento cita en la parroquia de la Puríssima Concepción de Nuestra Señora de esta villa, persona que únicamente compone dicha cofradía por hallarse en el día sin hermanos» (Lara 1995: 125). Tal como se aprecia, Garzón era el único hermano de la cofradía y, por tanto, su mayordomo.

Sin llegar a estos extremos, es evidente que no era dificil conseguir que las elecciones formalizasen unos turnos establecidos con anterioridad. Incluso a veces el propio desempeño de los cargos parece haber sido independiente de

\footnotetext{
9 Ibídem, fol. 51 v.

10 ADH, Justicia, Huelva, leg. 304 (ant.), Pleito de «la hermandad de Nuestra Señora del Rosario»..., 1727, fol. 112 r.

11 Ibídem, fol. $116 \mathrm{v}$.

$12 \mathrm{AMH}$, Fondo Diego Díaz Hierro, Libro de acuerdos de la hermandad del Santo Entierro y Nuestra Señora de la Soledad, fols. 51 r. y 52 r.
} 
la convocatoria de elecciones, como se muestra en algún acuerdo de cabildo de la hermandad del Santo Entierro que afirmaba «que, aunque está nombrado por hermano mayor desta cofradía a nuestro hermano don Juan Lorenzo Picón, no consta este nombramiento por acuerdo de la hermandad, y por este ratificaron dicho nombramiento». ${ }^{13}$ Es decir, que existía oficialmente hermano mayor, o mayordomo, con anterioridad a que fuera elegido en cabildo.

En otros casos, como en el de la hermandad de Nuestra Señora del Rosario, el cuerpo electoral no coincidía con el conjunto de todos sus hermanos, sino con una parte restringida encabezada por la directiva saliente. Aunque algo ambiguas, sus reglas así lo dictaban:

Estando en nuestro cavildo se aparten dos cofrades, los más ançianos, y el prioste y el maiordomo y alcaldes viejos y el escrivano y diputados, y más aquellos que nuestro cavildo mandare, a los quales se les da todo poder para que ellos señalen y nombren por ofiçiales a aquellas personas que vieren que son háviles y sufiçientes y de buena conçiencia, para que gasten y exerciten y reçiban todo quanto a nuestra hermandad convenga. ${ }^{14}$

Como afirma Rumeu de Armas (1981: 223), esta intervención de los cargos salientes en la elección de sus sucesores era bastante habitual en España y, en algunos casos, los nombraban directamente sin intervención del cabildo de hermanos. En otras ocasiones, bastaba con la simple ratificación de este, según ha visto Morgado García en Cádiz (1992: 49). Hay que aclarar, eso sí, que la de Nuestra Señora del Rosario de Huelva era hermandad de negros y a ella pertenecían tanto esclavos como libertos, lo que hacía que a la autoridad eclesiástica le pareciera necesario mantener un control más directo sobre el nombramiento de cargos, sobre todo porque los amos ejercían sobre los esclavos una influencia decisiva.

Lo cierto es que en el siglo XVII fueron elegidos esclavos como hermanos mayores, lo que hizo surgir graves conflictos con los libertos de la cofradía. Francisco de Moya, «de color moreno, hermano más antiguo de la hermandad de Nuestra Señora del Rosario», cursó en 1677 una demanda al provisor del arzobispado de Sevilla en que le hacía partícipe de los siguientes pormenores:

La causa de haber benido entonces a disminusión la dicha cofradía fue porque daba los ofizios de mayordomo, alcaldes y los demás a negros sclabos que, amparados de el fabor de sus amos, no hasían más que gastar lo que juntaban de limosnas sin ser de utilidad a la dicha cofradía los tales gastos, antes sí de mucho perjuicio por consumirse las limosnas, y esto mismo empiessa a correr y se a de bolber a destruir la dicha cofradía si se prosigue en que los dichos sclabos tengan ofizio en ella, para cuio remedio a vuestra merced suplico mande despachar su mandamiento, las sensuras presisas y otras penas contra todos los hermanos de la dicha cofradía para que no nombren en los cabildos que hissieren por mayordomos, alcaldes ni ofizios de la dicha cofradía a ninguno de los negros sclabos, así por las razones dichas como porque, siendo tales mayordomos sclabos, no se le puede proseder contra ellos a que den quentas, as por ser sus amos poderosos como por estar spuestos a

13 Ibídem, fol. 52 v.

$14 \mathrm{ADH}$, Justicia, Huelva, leg. 304 (ant.), Pleito de «la hermandad de Nuestra Señora del Rosario»..., 1727, fol. 116 v. que cada y quando que sus amos quieran benderlos lo hagan y no aia forma para hazer diligencia ninguna con ellos para que den quenta de las limosnas o alajas que entran en su poder. ${ }^{15}$

El vicario añadió a la denuncia otros inconvenientes derivados del nombramiento de esclavos y, además, se hizo notorio que, a veces, el acceso de los mismos a los cargos se hacía conculcando cualquier procedimiento de tipo electoral. Así, se argumentó que

Thomás Hidalgo, esclavo del lizenciado don Joseph Ordoñes, cura más antiguo de la dicha iglesia, fue mayordomo de la dicha hermandad sin nombramiento ni elezión de los hermanos, más que con la mano poderosa de dicho su amo, el qual como tal cura más antiguo y beneficiado de dicha iglesia se intrometió a la administración y cobransa de la dicha mayordomía por el dicho su esclavo. ${ }^{16}$

Al final, viendo las irregularidades que se estaban cometiendo en el funcionamiento de la hermandad, el provisor acabó ordenando que "se despache mandamiento para que no se eligan ofiçiales morenos esclavos de la cofradía de Nuestra Señora del Rosario de la villa de Huelba». ${ }^{17}$

Si bien no de una manera tan drástica, no es infrecuente encontrar hermandades en las que se reservaba el acceso a los cargos a los candidatos que reunieran unas características determinadas previamente o que, simplemente, fueran seleccionados por la autoridad vigilante. En efecto, no siempre podía ser candidato cualquier hermano. En la esclavitud de la Merced era directamente el padre comisario el que, antes de una elección, proponía «sujetos duplicados de los más celosos y observantes ${ }^{18}$ para cada cargo; en la de los Dolores, el nombramiento de los candidatos era más complejo, pero también quedaba atado: el padre comisario exhortaba
al Secretario, para que de la tabla de los Congregantes, entresaque, y escriba en un arancel, los que sean los más idóneos. Venido el día primero de Pasqua de Resurrección, se juntarán los de la Junta secreta en la sala para este fin prevenida: $Y$ después de implorada la gracia del Espíritu Santo, se harán las Ternas para cada oficio de las personas más idóneas del arancel (Reglas 1774: 16-17).

Los más celosos y observantes; los más idóneos. Como vemos, en las esclavitudes, mucho más cerradas que las demás hermandades, era el representante eclesiástico el que proponía una dupla o una terna de candidatos para elegir entre ellos a los cargos.

15 ADH, Justicia, Huelva, leg. 29, exp. 9, «Pleito de Francisco de Moia, vezino de la villa de Huelva, hermano más antiguo de la cofradía de Nuestra Señora del Rosario, sita en la parrochial de señor San Pedro de la dicha villa, con los hermanos de color moreno de dicha cofradía», 1677, fol. 2 r.

16 ADH, Justicia, Huelva, leg. 29, exp. 10, Comunicación de Francisco de Moya al arzobispado de Sevilla, 1678, fol. $1 \mathrm{r}$.

17 ADH, Justicia, Huelva, leg. 29, exp. 9, «Pleito de Francisco de Moia»..., 1677, fol. $11 \mathrm{v}$.

$18 \mathrm{ADH}$, Justicia, Huelva, leg. 29, exp. 15, «Copia y traslado de la regla y capítulos de la hermandad y esclavitud de Nuestra Señora de la Merced, zita en la iglesia del convento de religiosos mercenarios descalsos de la villa de Huelva, aprobada por el señor provisor deste Arzobispado en 22 de junio de 1754», fol. 6 r. 
En cualquier caso, no hacía falta una restricción formal de los candidatos para que esa limitación existiera tácitamente. En principio, por los riesgos económicos que suponía, pocos hermanos estaban en condiciones de asumir el reto de ser hermano mayor o mayordomo. Cuando, en 1697, el visitador arzobispal José Morales Varejón tomó las cuentas a los mayordomos de las cofradías de Huelva, resultaron los siguientes alcances o déficits:

La del Santíssimo de La Concepción no tubo alcanze.

La del Santíssimo en San Pedro fue alcançada la cofradía en 755 reales.

La de Jesús Nazareno sita en San Francisco de Paula queda cometida al vicario para su quenta por no aber estado en la villa su mayordomo.

La de Nuestra Señora de el Rosario fue alcançado su mayordomo en 191 reales.

La de Nuestra Señora de los Reyes es alcançada en 6.223 maravedís.

La de las Ánimas en San Pedro fue alcanzada en 45.351 maravedís.

De Nuestra Señora de la Zinta fue alcançado el mayordomo en 445 maravedís.

De la Vera Cruz en La Concepción fue alcançado el mayordomo en 318 reales y quarto. ${ }^{19}$

Como el mayordomo o el hermano mayor debía responder de los saldos en contra que resultasen de la toma de cuentas, era evidente que solo podían asumir dicha responsabilidad quienes presentaran suficiente solvencia o respaldo económico. A la propia cofradía, por tanto, le interesaba que los resultados de las elecciones auparan a los cargos a sus hermanos de mayor caudal y, en consecuencia, existió un filtro económico y social que se consensuaba sin necesidad de explicitarlo en unos estatutos. A esta especie de «orden natural» emanada de la jerarquía socioeconómica se unía el escaso nivel de alfabetismo habitualmente presente en el cabildo de hermanos, lo que hacía también aconsejable que los principales cargos se repartieran entre los miembros de la buena sociedad local, de modo que las elecciones quedaban condicionadas bajo muchas perspectivas.

El período de tiempo más común para el desempeño de los cargos era, como en el Cabildo municipal, el de un año, si bien en esto existía cierta flexibilidad. En este sentido, la cofradía de Nuestra Señora del Rosario regulaba por sus estatutos que, "si el tal maiordomo fuere tal que por su buen servicio merezca el cargo, lo tenga otro año, no embargante que se ha de hazer cada año oficiales». ${ }^{20} \mathrm{El}$ "buen servicio» al que aquí se aludía era obviamente el económico. Realmente, si la gestión era eficaz o provechosa, se solía alargar en lo posible la permanencia del mayordomo o del hermano mayor al frente de una hermandad, no solo cuando las cuentas mostraban superávits, sino cuando se entregaban donaciones o legados en épocas en las que el mecenazgo o la obra pía eran ingredientes fundamentales de la buena fama. En esos casos, las elecciones pasaban a un segundo término y la pulcritud de los procedimientos electorales dejaba paso, ante la aquiescencia general, al

19 AAS, Visitas pastorales, leg. 1.343, Visita pastoral de José Morales Varejón, 1697, s/fol.

20 ADH, Justicia, Huelva, leg. 304 (ant.), Pleito de «la hermandad de Nuestra Señora del Rosario»..., 1727, fol. 116 v. beneficio material de la asociación. Eso sucedió con don Diego de Guzmán y Quesada, benefactor de la cofradía del Santo Entierro y de su ermita de La Soledad en el último tercio del siglo XVII, que, según referencias de su sucesor, fue hermano mayor de ella «toda su vida». ${ }^{21} \mathrm{Al}$ fin y al cabo, ser hermano mayor o mayordomo de una cofradía era uno de los símbolos visibles de la preeminencia social de una familia y, cuando esa influencia se ejercía, normalmente las elecciones no presentaban ninguna posibilidad de alterar la realidad.

Esa prolongación del cargo más allá del período de un año no era rara: el prior de la esclavitud de los Dolores «exercitará su oficio los dos años» (Reglas 1774: 19), en tanto que los demás puestos eran anuales, y a fines del siglo XVIII sería también bienal la directiva completa de la cofradía del Santo Entierro, pues sus elecciones generales se convocaban regularmente en año par. En todo caso, la tendencia fue a fijar en un año la duración de los cargos de hermandad, e incluso el propio Santo Entierro, en 1808, acordaría finalmente reducir sus plazos de dos años a uno.22

Para las elecciones, se celebraba cabildo general de hermanos en fecha que podía quedar establecida en estatutos, aunque generalmente variaba con facilidad. En las reglas de la hermandad de Nuestra Señora de los Reyes se estipulaba con precisión "que el domingo quarto del mes de enero de cada año se junten los cofrades ${ }^{23}$ para elegir los nuevos cargos; ese mismo domingo cuarto del año se reunían los hermanos del Dulce Nombre, mientras que los de Jesús Nazareno lo hacían el tercero. ${ }^{24}$ Convocar las elecciones en domingo era lo habitual, aunque también sucedía que, elegido un mes, la fecha concreta fuera bailando en el calendario sin ajustarse a norma fija. Así ocurría, especialmente, en la cofradía del Santísimo Rosario, en la que (después de celebrarlos el día 2 de febrero, festividad de la Candelaria, entre 1707 y 1711) se convocaban los cabildos en el mes de agosto de cada año, aunque los días no seguían ninguna reglamentación: era el mismo caso, aunque esta vez en primavera, de la hermandad del Santo Entierro.

En otras ocasiones, sin embargo, el hacer coincidir las elecciones con ciertas fiestas particularmente significativas se perseguía con cierto énfasis. La esclavitud de la Merced optaba por «el día quinse de agosto, en que se ha de haser la fiesta por la hermandad, para el cavildo de elecciones de hermano mayor y demás ofisiales», ${ }^{25}$ y la esclavitud de los Dolores establecía "cómo se han de elegir Oficiales el día segundo de Pasqua de Resurrección» (Reglas 1774: 16). Días de fiesta para la reunión: solemnidad sobre solemnidad. Incluso cuando las reglas no imponían necesariamente una fecha, solía aconsejarse, como hacía la de

21 ADH, Justicia, Huelva, leg. 2, exp. 33, Solicitud de don Diego José Ferro Gupil al arzobispado de Sevilla para suceder en el patronato de la ermita de La Soledad de Huelva, 1693, fol. 2 r.

22 AMH, Fondo Diego Díaz Hierro, Libro de acuerdos de la hermandad del Santo Entierro y Nuestra Señora de la Soledad, fol. 51 r. y v.

${ }_{23}$ ADH, Justicia, Huelva, leg. 304 (ant.), Pleito de «la hermandad de Nuestra Señora del Rosario»..., 1727, fol. 78 r.

24 Archivo Histórico Nacional, Clero, Libros, 4.619, Libro de apuntamiento de memorias perpetuas del convento de Nuestra Señora de la Victoria de Huelva, fol. $159 \mathrm{r}$.

$25 \mathrm{ADH}$, Justicia, Huelva, leg. 29, exp. 15, «Copia y traslado de la regla y capítulos de la hermandad y esclavitud de Nuestra Señora de la Merced»..., fol. $6 \mathrm{r}$. 
la hermandad de San Antonio, que «un domingo o fiesta, después de haver hecho la fiesta del vien aventurado y glorioso Sancto Antonio de Padua, se haga cavildo para elegir ofiçiales». ${ }^{26}$

Es fácil dibujar el ambiente solemne en que las elecciones se celebraban y el papel nada desdeñable que correspondía al marco espacial, en cuanto a hieratismo y dimensión trascendental del momento. Los lugares de votación se situaban normalmente en los altares de las imágenes titulares, "y en el sitio que se elija para dicho acto se tendrá una mesa con un Santo Christo con dos velas y los libros y constituziones de la hermandad». La presencia, tal como se vio, del vicario y su notario apostólico aportaba al acontecimiento la rigidez de la vigilancia clerical y, bajo su presidencia, rara vez delegada, y tras la toma de cuentas al mayordomo saliente, "se tocará la campanilla para hazer el nuevo nombramiento». ${ }^{27}$

En un espacio y un tiempo sacralizados, las elecciones no eran un ejercicio del todo humano. En realidad, se trataba de un acto trascendente, a lo divino, por el que una comunidad unida en lo religioso se iba a proveer a sí misma de una cabeza que pudiera traer al conjunto los mejores frutos materiales y espirituales. En el fondo, el momento de las elecciones estaba concebido como parte de una auténtica función religiosa, y la forma y el lenguaje que lo envolvían eran los de esa función:

Se junten los cofrades en la iglesia de San Pedro desta villa de Huelva - decían los estatutos de Nuestra Señora de los Reyes-, donde está la imagen de Nuestra Señora, y se diga una missa solemne al Espíritu Sancto o a Nuestra Señora, implorando el divino auxilio para que provea a dicha cofradía un mayordomo apto y al propósito para el aumento della. ${ }^{28}$

En las esclavitudes, era el padre comisario quien tomaba las riendas del acontecimiento, "y para que este (el acto de la elección) se execute en paz y unión hará el padre comisario una exortasión espiritual a este fin ", ${ }^{29}$ exhortación que en los estatutos de la esclavitud de los Dolores se hallaba particularmente definida:

El día segundo de la Pasqua a la tarde, se harán los acostumbrados Exercicios: exortará el padre Comisario a todos con una breve oración, a que elijan a las personas más convenientes para el aumento de la Congregación, y servicio de nuestro Señor; y acabados los Exercicios se saldrán todos los que no fuesen profesos, porque solo los que lo son tienen voto, y después de implorada la gracia del Espíritu Santo con el Hymno: Veni creator Spiritus, etc. se publicarán las ternas (Reglas 1774: 16).

En sí misma, la votación no tenía excesivas complicaciones; la esclavitud de los Dolores, eso sí, la organizaba en tres jornadas: el primer día de Pascua de Resurrección para

26 ADH, Justicia, Huelva, leg. 304 (ant.), Pleito de «la hermandad de Nuestra Señora del Rosario»..., 1727, fol. 120 r.

${ }^{27} \mathrm{ADH}$, Justicia, Huelva, leg. 29, exp. 15, «Copia y traslado de la regla y capítulos de la hermandad y esclavitud de Nuestra Señora de la Merced»..., fol. $6 \mathrm{r}$.

28 ADH, Justicia, Huelva, leg. 304 (ant.), Pleito de «la hermandad de Nuestra Señora del Rosario»..., 1727, fol. 78 r. y v.

29 ADH, Justicia, Huelva, leg. 29, exp. 15, «Copia y traslado de la regla y capítulos de la hermandad y esclavitud de Nuestra Señora de la Merced»..., fol. 6 r. la votación previa (en junta secreta) de las ternas de candidatos; el segundo día de Pascua para la votación de los oficiales mayores; el tercero, para los menores. Si los resultados de las votaciones eran claros, el nombramiento de los nuevos oficiales se realizaría de forma automática. Si había empate, el intervencionismo del clero obtenía un nuevo campo para actuar. En la propia esclavitud de los Dolores, «si acaso los votos salen iguales, pertenece al Comisario declarar por Prior, al que juzgare más conveniente, y decidirá» (Reglas 1774: 18), mientras que, en la hermandad de Nuestra Señora de los Reyes, según quedó ya apuntado, "estando discordes los hermanos en los votos» tenía el vicario facultad para definir. ${ }^{30}$

En condiciones normales, sin embargo, todo era directo y mecánico. Una vez comenzado el acto electoral, las reglas de la esclavitud mercedaria referían que «se procederá a tomar los votos por el secretario y, fenesidos todos, se regularán por dicho secretario y padre comisario, y se declarará la elección por los que para los respectivos empleos tubieron mayor número de botos, y luego se pondrán cada uno en el lugar que le corresponda y dejan los ofisiales que salen, y los nuevamente electos prometerán cumplir con sus correspondientes obligaziones», ${ }^{31}$ quedando formada la nueva junta directiva. En realidad, una vez emitidos los resultados, el juramento y toma de posesión de los nuevos cargos se convertían para los elegidos en un acto obligatorio, pues la entrada en una hermandad suponía la aceptación tácita por parte del hermano, cuando el cabildo general así lo estimara, de los cargos de responsabilidad que eventualmente debiera por turno o conveniencia desempeñar: "y el que fuere elexido para qualquiera destos ofiçios, sin que lo quisiere azetar, pague de pena dos libras de zera y que todavía lo sea, y si no lo quisiere ser lo pague doblado», establecía finalmente la hermandad de San Antonio de Padua. ${ }^{32}$ Se supone, pues, que no todos los candidatos lo eran voluntariamente o que en no pocas ocasiones las elecciones se realizaban sin previa presentación de candidaturas: buen recurso para que los hermanos de caudal no rehuyesen la obligación moral de contribuir, a través de una mayordomía, al sostenimiento económico de la comunidad.

La sesión terminaba envuelta en esa misma nebulosa en que la función religiosa y el hieratismo institucional tendían a confundirse: «Fenesido en esta forma el cavildo, saldrán todos formados con su pendón y pasarán a la iglesia de dicho convento cantando el Te Deum en hasimiento de gracias», dictaban los estatutos de la esclavitud de la Merced. ${ }^{33}$ El mismo Te Deum y la Salve cantaban los esclavos de los Dolores tras elegir oficiales mayores, y al final de todo el proceso,

se irá el Padre Comisario con todos los oficiales nuevos ante el Altar de nuestra Madre Dolorosa, y arrodillados

30 ADH, Justicia, Huelva, leg. 304 (ant.), Pleito de «la hermandad de Nuestra Señora del Rosario»..., 1727, fol. 78 v.

$31 \mathrm{ADH}$, Justicia, Huelva, leg. 29, exp. 15, «Copia y traslado de la regla y capítulos de la hermandad y esclavitud de Nuestra Señora de la Merced»... fol. 6 r.

32 ADH, Justicia, Huelva, leg. 304 (ant.), Pleito de «la hermandad de Nuestra Señora del Rosario»..., 1727, fol. 120 r.

$33 \mathrm{ADH}$, Justicia, Huelva, leg. 29, exp. 15, «Copia y traslado de la regla y capítulos de la hermandad y esclavitud de Nuestra Señora de la Merced»... fol. $6 \mathrm{r}$. 
todos, les dirá el padre Comisario, cómo la Venerable Congregación les ha elegido Oficiales suyos, y les exortará al cumplimiento de sus ofiçios, y obligaçiones, como aquí se contienen, y les confirmará haciendo la señal de la Crus, y diciendo: Yo los confirmo in nomine Patris, el Filij, et Spiritus Sancti. Y de allí se irán a tomar posesión de los puestos, que han de ocupar todo el tiempo de sus empleos. El Secretario escribirá todo lo hecho en el Libro de Acuerdos, y en una tabla pondrá todos los oficiales, la qual estará en público siempre, para que todos sepan la obligaçión que tienen (Reglas 1774: 18)

Bajo el lenguaje casi sacramental de los cabildos de elecciones, latía en esencia una doble afirmación: afirmación de la hermandad como institución, como continuidad ordenada en el tiempo; y afirmación de un orden jerárquico que reproducía, en maqueta, lo que ya estaba impreso en la sociedad de la que se nutría. Cuando una comunidad de tipo religioso, independientemente de su naturaleza devota, se organizaba y funcionaba, las relaciones que emergían entre sus miembros dejaban de pertenecer al ámbito de lo piadoso para formar parte de un mundo institucional definido por las relaciones de poder entre sus miembros. $Y$ en este mundo de poder, cuya pequeña escala no ocultaba la fortaleza de su jerarquía, la existencia de las elecciones suponía, frente a la mayor apertura social del turno y la insaculación, un instrumento para garantizar el orden.

\section{CONCLUSIONES}

Pese a que, aparentemente, las hermandades religiosas en la España del Antiguo Régimen constituían organizaciones de funcionamiento representativo que contrastaban con la política absolutista de la Corona, en realidad no fue del todo así. Ni siquiera las elecciones a sus cargos directivos garantizaban la circulación de los hermanos al frente de ellos y, aun en los casos en los que los estatutos en teoría abrían el gobierno de las hermandades a aquellos que simplemente obtuvieran un mayor número de votos en los escrutinios, en la práctica se establecieron numerosos controles y filtros para vigilar el procedimiento y determinar sus resultados. En su mayor parte, las elecciones en las hermandades del Antiguo Régimen se sostuvieron sobre un voto vigilado y, salvo excepciones, su hipotética representatividad no existió realmente.

En principio, en aquellas hermandades y cofradías cuyo cuerpo de hermanos gozaba de suficiente homogeneidad social (caso de las universidades de clérigos y las hermandades compuestas por la buena sociedad local, a menudo cerradas al resto), la existencia del turno o la insaculación para el acceso a los cargos era su mayor garantía de transparencia y representatividad: tanto uno como otro procedimiento eludían bien la posibilidad de la coerción o la influencia decisiva. Sin embargo, en aquellas otras hermandades - la gran mayoría - que disponían de un conjunto de miembros socialmente heterogéneo, el sistema de votaciones se convertía en una forma particularmente eficaz de controlar, mediante determinados mecanismos de vigilancia e intervención, quiénes iban a ser las personas que rigieran la hermandad.

No era muy difícil que las elecciones reprodujeran los resultados previstos o deseados por la autoridad eclesiástica y los hermanos de mayor peso de la cofradía. Sin un censo o listado actualizado de miembros con derecho a voto y, en cualquier caso, con unos índices de participación electoral habitualmente muy bajos, no existían muchas posibilidades de que las elecciones escaparan al control del vicario, quien las presidía, o de los hermanos o familias tradicionalmente vinculadas al desempeño de los cargos. A ello se añadía un par de factores más, de carácter general, que no pueden dejar de tenerse en cuenta. Por un lado, el alto número de cofrades analfabetos, incapaces de votar en secreto mediante una cédula escrita, hacía preciso que su voto se emitiera públicamente en voz alta o con la participación de otros hermanos, lo que permitía la existencia de diversas formas de presión, explícitas o sutiles. Por otro, la necesidad de que el hermano mayor o mayordomo respondiera con sus bienes a los recurrentes déficits que presentaba la contabilidad de la cofradía, fiscalizada por los visitadores de la diócesis, impedía que la gran mayoría de miembros de una hermandad pudiera optar, por su propia precariedad económica, a gobernar sus destinos.

Estos eran filtros que, por sí mismos, conducían normalmente a la formulación de un consenso entre los hermanos sobre las personas que podrían acceder a los cargos de modo satisfactorio, consenso creado sobre la premisa de que solo aquellos que disponían de capacidad económica e influencia social estaban en condiciones de dirigir la hermandad y garantizar su mantenimiento. Tal pacto implícito convenía a todos: a quienes desempeñaban los cargos y obtenían algunos honores simbólicos a cambio de realizar determinados desembolsos económicos, a la autoridad eclesiástica interesada en mantener la estabilidad y tranquilidad de las asociaciones religiosas y, finalmente, al cuerpo de hermanos, que podía sentirse seguro bajo el beneficio y amparo de los cofrades de mayor peso. Eso significa que los sistemas de vigilancia y control fueron, las más de las ocasiones, asumidos con naturalidad por todas las partes, de modo que pocas veces desembocaron en formas de coacción expresas y visibles. Prueba de ello es la evidencia de que existió un cierto turnismo incluso en hermandades que, formalmente, celebraban elecciones abiertas para el acceso a los cargos. En el fondo, con la concurrencia de todos los factores mencionados anteriormente, no había especiales problemas en que los hermanos, o al menos la más influyente parte de ellos, lograsen un consenso previo que las votaciones iban a sancionar sin excepción seguidamente. Consenso quiere decir, naturalmente, que los más poderosos accedían a los cargos con el asentimiento y beneplácito de los demás.

En general, eso ya funcionaba así, tácitamente, en épocas en que la mayoría de las hermandades se organizaba al margen de toda regla o estatuto, aunque en esos casos no había manera de fijar y asegurar un procedimiento. Cuando, por mandato de la autoridad eclesiástica (y, luego, del Consejo de Castilla), se demandó a las hermandades la presentación de reglas en que sus modos de funcionar se establecieran por escrito, como instrumento de control, los textos introdujeron normalmente procedimientos que tendían a garantizar que los resultados de las votaciones estuvieran de acuerdo con el reparto "natural» de la sociedad. Se trataba, en definitiva, de que las hermandades reprodujeran en maqueta los sistemas de influencia y poder del 
conjunto de la sociedad, que se tenían por buenos, y de que el acceso a los cargos se llevase a cabo sin contradecir esos esquemas. Hubo hermandades cuyos cargos salientes nombraban directamente a sus sucesores o presentaban unas ternas de candidatos; las hubo en las que los hermanos tenían diferente número de votos; incluso las hubo en las que no existían candidaturas o en las que los cargos directivos ejercían su responsabilidad aun antes de que se celebrasen las votaciones. Hubo también quienes permanecieron toda su vida de hermanos mayores a pesar de la existencia de elecciones anuales.

En el fondo, no existió en el seno de las hermandades un concepto demasiado claro de la representatividad de los cargos o, al menos, esa representatividad nunca se refirió al conjunto completo de los hermanos. Probablemente, la sacralización del voto en las sociedades liberales y democráticas proyecta hoy sobre las hermandades de la Edad Moderna una imagen de asociaciones representativas que no tiene nada que ver con su funcionamiento real: de ahí que, en su día, estos sistemas electorales subsistieran sin problemas en el contexto de la política absolutista que dio forma global a la sociedad. La votación, en consecuencia, no fue tanto un vehículo de legitimidad y responsabilidad colectiva en el acceso a los cargos como un instrumento mediatizado de control, que venía a sustituir la ingobernable transparencia del turno o la insaculación. Ya hemos dicho que no parece que fuera necesaria una coacción muy explícita para lograr que los resultados de las votaciones reprodujeran el orden social dominante. No en vano, uno de los mayores logros ideológicos de los poderes del Antiguo Régimen fue conseguir - no en todos y no siempre, claro, pero sí entre la mayoría y la mayor parte del tiempo- que sus sistemas de jerarquía e influencia social se extendieran por todos los ámbitos de la realidad mediante la idea, básica pero eficaz, de que respondían al orden natural de las cosas.

\section{FUENTES}

Constituciones del Arçobispado de Sevilla, hechas i ordenadas por el Ilustríssimo i Reverendísimo Señor Don Fernando Niño de Guevara, Cardenal i Arçobispo de la S. Iglesia de Sevilla, en la synodo que celebró en su Cathedral, año 1604. 1609. Sevilla: Imprenta de Alonso Rodríguez Gamarra.

Morales, Joseph Isidoro. 1797. Memoria matemática sobre el cálculo de la opinión en las elecciones. Madrid: Imprenta Real por Pedro Julián Pereira.

Reglas, y obligaciones, que han de observar los que vistieren el Sagrado Escapulario, y se asentaren por siervos, y esclavos de María Santísima Dolorosa, en la congregación fundada y establecida en el convento de los RR. PP. Mercenarios Descalzos de la villa de Huelva. 1774. Cádiz: Imprenta de Manuel Espinosa de los Monteros.

\section{BiBLIOGRAFÍA}

Carbajal López, David. 2016. «Mujeres y reforma de cofradías en Nueva España y Sevilla, ca. 1750-1830». Estudios de Historia Novohispana 55: 64-79. https://doi.org/10.1016/j.ehn.2016.04.002

Díaz Hierro, Diego. 1972. Huelva y el apóstol Santiago. Sevilla: ed. del autor.

Franco Rubio, Gloria Ángeles. 1995. «Asociacionismo femenino en la España del siglo XVIII: las Hermandades de Socorro de Mujeres». Cuadernos de Historia Moderna 16: 179-199.

Galán Parra, Isabel. 2004. Las ordenanzas ducales del año 1504. Administración y economía en los señoríos de los duques de Medina Sidonia. Almonte: Ayuntamiento de Almonte.

González Cruz, David. 1995. "Cofradías y asociacionismo religioso en la Huelva del Antiguo Régimen: mentalidad, organización y recursos económicos (1700-1800)». En Actas del Il Congreso de Historia de Andalucía. Andalucía Moderna, tomo III, 189-208. Córdoba: Junta de Andalucía - Cajasur.

Lara Ródenas, Manuel José de. 1989. «Las hermandades religiosas en la Huelva de los siglos XVI y XVII». El contraguía 1989: 22-23.

Lara Ródenas, Manuel José de. 1995. Religiosidad y cultura en la Huelva moderna. Huelva: Diputación Provincial de Huelva.

Lara Ródenas, Manuel José de. 1998. La Ilustración en las sacristías. El vicario de Huelva y las respuestas a Tomás López. Huelva: Junta de Andalucía.

López Muñoz, Miguel Luis. 1992. «Las cofradías de la ciudad de Granada en la segunda mitad del siglo XVIII». En Gremios, Hermandades y Cofradías. Una aproximación científica al asociacionismo profesional y religioso en la Historia de Andalucía, tomo II, 55-72. San Fernando: Ayuntamiento de San Fernando.

López Vacas, Ángela. 2014. La labor social de las cofradías durante el Antiguo Régimen en Fuente de Cantos. Trujillo: Asociación Cultural Coloquios Históricos de Extremadura. http://www.chdetrujillo. com/la-labor-social-de-las-cofradias-durante-el-antiguo-regimenen-fuente-de-cantos/. [Última consulta: 17/10/2018].

Mena García, Carmen. 2000. «Las hermandades de Sevilla y su proyección americana: estudio comparativo de la cofradía de Nuestra Señora de los Ángeles o 'de los negritos' de Sevilla y de la cofradía de Santa Ana de Panamá». En Estrategias de poder en América Latina, coordinado por Pilar García Jordán et al., 129-150. Barcelona: Universitat de Barcelona.

Mira Caballos, Esteban y Fernando de la Villa Nogales. 1999. Carmona en la Edad Moderna. Religiosidad y arte, población y emigración a América. Sevilla: Muñoz Moya.

Moreno, Isidoro. 1997. La antigua hermandad de los Negros de Sevilla. Etnicidad, poder y sociedad en 600 años de Historia. Sevilla: Universidad de Sevilla.

Morgado García, Arturo. 1992. «Cofradías y hermandades en el Cádiz de los siglos XVII y XVIII». En Gremios, Hermandades y Cofradías. Una aproximación científica al asociacionismo profesional y religioso en la Historia de Andalucía, tomo I, 43-66. San Fernando: Ayuntamiento de San Fernando.

Pérez González, Silvia María. 2016. «Nuevas aportaciones al estudio de las cofradías y hermandades en la Castilla bajomedieval: el ejemplo de Jerez de la Frontera». Hispania Sacra 138: 503-520. https:// doi.org/10.3989/hs.2016.032

Rumeu de Armas, Antonio. 1981. Historia de la Previsión Social en España. Cofradías - Gremios - Hermandades - Montepíos. Barcelona: Ediciones El Albir.

Sintomer, Yves. 2012. "Selección aleatoria, autogobierno republicano y democracia deliberativa». Enrahonar. Quaderns de Filosofía 48: 133-156. 